\title{
Management priorities for seawater desalination plants in a marine protected area: A multi-criteria analysis
}

\author{
Nadine Heck ${ }^{a, b}$, Adina Paytan ${ }^{b, c}$, Donald C. Potts ${ }^{e}$, Brent Haddad ${ }^{d}$, Karen Lykkebo \\ Petersen ${ }^{\mathrm{c}}$ \\ ${ }^{a}$ Department of Ocean Sciences, University of California, Santa Cruz, 1156 High Street, \\ Santa Cruz, CA 95064, USA \\ ${ }^{b}$ Institute of Marine Sciences, University of California, Santa Cruz, 1156 High St., Santa \\ Cruz, CA 95064, USA \\ c Department of Earth and Planetary Sciences, University of California, Santa Cruz, 1156 \\ High Street, Santa Cruz, CA 95064, USA \\ 'Environmental Studies, University of California, Santa Cruz, 1156 High St., Santa Cruz, \\ CA 95064, USA \\ e Department of Ecology and Evolutionary Biology, University of California, Santa Cruz, \\ 1156 High Street, Santa Cruz, CA 95064, USA
}

\section{Abstract}

The development of seawater desalination plants to increase water reliability in coastal areas poses a threat to the health of near shore marine ecosystems and may affect the effectiveness of marine protected areas (MPAs) that have been established to meet international conservation targets. This paper applies a multi-criteria analysis approach to quantify stakeholder groups' priorities for seawater desalination plants that have been proposed in communities adjacent to a National Marine Sanctuary. All groups placed the highest importance on minimizing environmental impacts on protected areas and endangered species that could be affected by water intake and brine discharge emphasizing the need for integrated land and sea conservation. Minimizing socio-economic impacts on coastal communities was much less important. Stakeholders also weighted reducing pressure on water levels in rivers, streams, and aquifers as more important than increasing water for residential consumption, which may foster coastal growth rather than replacing water taken from other sources. The study further revealed differences in the importance of multiple management objectives among stakeholder groups, which highlights the need to elicit distinct priorities of all groups to understand concerns and potential conflicts of desalination with existing marine users. The analysis of consistency ratios revealed that around half of all surveyed stakeholders had high inconsistencies in their responses, which suggests either a lack of understanding of desalination, or reflects the complexity of establishing desalination plants in coastal areas adjacent to a marine protected area. 
This is the accepted manuscript of a paper published in Marine Policy. The final version may be accessed at https://dx.doi.org/10.1016/j.marpol.2017.09.012.

\section{Introduction}

Seawater desalination is increasingly being pursued in coastal regions worldwide, with more than 18,000 desalination plants already in operation [38]. The technology is used to alleviate shortages in drinking water in coastal areas due to changing weather patterns, recurring droughts, saltwater intrusion into coastal aquifers, and growth of coastal populations and industries. Despite the advantage of providing a water supply option independent of climate, seawater desalination plants also have the potential to negatively impact coastal ecosystems and communities, depending on the design, locations, and local context of these plants $[22,43,8]$. Examples of socio-economic impacts include increased price of water-since the technology is relatively expensive $[10,15,33,63,9]$, loss of public access to coastal areas, disruption of commercial and recreational activities, and aesthetic alterations of coastal landscapes $[43,6,64]$. Indirect environmental impacts on marine ecosystems, such as ocean acidification and sea-level rise, may occur due to the high energy consumption of desalination plants and subsequent increase in greenhouse gas emissions [46,9]. Direct environmental impacts may include degradation of marine habitats (e.g., loss of seagrass beds), mortality of bottom-dwelling organisms $[16,17]$, coastal eutrophication, changes in seawater quality, and changes in microbial communities and production due to brine discharge [4]. Other concerns are mortality of larvae and other organisms due to impingement and entrainment during seawater intake [34].

Desalination plants built in close proximity to marine protected areas (MPAs) may interfere with marine conservation efforts. MPAs are increasingly being established worldwide to meet national and international conservation targets. These areas are designated for many reasons such as securing or restoring marine biodiversity, managing fisheries and supporting the sustainable use of marine resources $[23,26,40,57]$. Water intake and brine discharge may reduce effective protection of values in MPA sites, or reduce the effectiveness of MPA networks, for example by reducing larval connectivity between MPAs [48].

Planning of desalination plants therefore requires careful balancing of ecological, social, and economic objectives, and the plants should be integrated into wider coastal zone management, since sectoral approaches to marine and coastal zone management typically fail [12]. However, systematic planning processes are often missing and desalination plants are usually established on a project to project basis.

In addition, engagement of coastal stakeholders in the planning process is critical and integral to many coastal and marine policies $[45,56,67]$. In the United States, gathering, weighting, and incorporating stakeholder input is an important part of coastal and marine resource management, including the development of desalination facilities [5] and management of MPAs [62]. To date, public input is solicited primarily in public meetings and comments on Environmental Impact Reports. Systematic assessments of quantitative preferences are commonly missing. Engaging coastal stakeholders, including local residents, in the early stages 
of the planning process provides critical information on management preferences for these plants and offers insights into social acceptability and support $[25,35,37,66]$.

Unlike research on organized stakeholder groups, studies exploring management priorities of coastal citizens who are not part of organized stakeholder groups are still very limited, even though the public can have substantial influences on coastal development and management decisions [45,53]. This study addresses this gap and explores coastal stakeholders' priorities for proposed seawater desalination facilities adjacent to a National Marine Sanctuary. Such an assessment is critical to account for local preferences in the planning of desalination plants and to facilitate a more systematic approach to the planning of new facilities. While previous studies have investigated public attitudes towards desalination plants $[24,30,41]$ and the acceptance of using desalinated water [19-21,65], an understanding of coastal stakeholders' management priorities for seawater desalination plants is lacking.

To quantify the importance of management objectives that should be considered in the planning process, a multi-criteria analysis (MCA) approach was applied. MCA refers to a collection of theories, methodologies and techniques that explicitly integrate and balance a set of criteria, and these methods have been widely used in environmental and natural resource management to facilitate balancing multiple objectives and interests [31,7]. In this study, the Analytical Hierarchy Process (AHP) was selected, a MCA method that allows evaluation of the relative priorities placed on competing criteria [58]. The approach is particularly useful for examining tradeoffs in situations when multiple management objectives cannot be optimized simultaneously [44]. While the AHP has been used in the context of multiple marine issues including fisheries [36,39,42], aquaculture [70], marine protected areas [28,32,52], and ecosystem services [45], the method has not been applied to quantify local preferences for desalination plants.

However, stakeholders' opinions on desalination in the context of MPAs have not been explored to date, even though desalination impacts may reduce the effectiveness of existing marine conservation efforts and may affect marine users who depend on protected marine ecosystems for their livelihoods and enjoyment. This study offers insights into coastal stakeholders' management priorities for the development of seawater desalination facilities by exploring (1) the relative importance of management objectives for proposed seawater desalination plants, (2) differences in priorities across stakeholder groups, (3) the influence of stakeholders' characteristics, including ocean use and livelihood dependency on management priorities, and (4) consistency in stakeholders' responses.

\section{Methods}

\subsection{Study area}

The importance of management objectives for seawater desalination plants was investigated prior to their establishment in multiple coastal communities situated around a National Marine Sanctuary in central California (Fig. 1). The Monterey Bay National Marine Sanctuary has been a federal marine protected area since 1992 and is governed by the National Oceanic and 
Atmospheric Administration (NOAA). The Sanctuary encompasses a shoreline length of 276 miles and an area of 6094 square statute miles. The marine ecosystem in Monterey Bay is highly diverse and productive and contains one of North America's largest underwater canyons. Commercial fishing and marine recreation are allowed within the sanctuary, but oil drilling, ocean dumping, and sea bed mining are prohibited [49]. Since water intake and brine discharge can affect marine ecosystems, the Sanctuary has developed a Desalination Action Plan that calls for a regional planning effort for desalination within the boundaries of the Sanctuary [50].

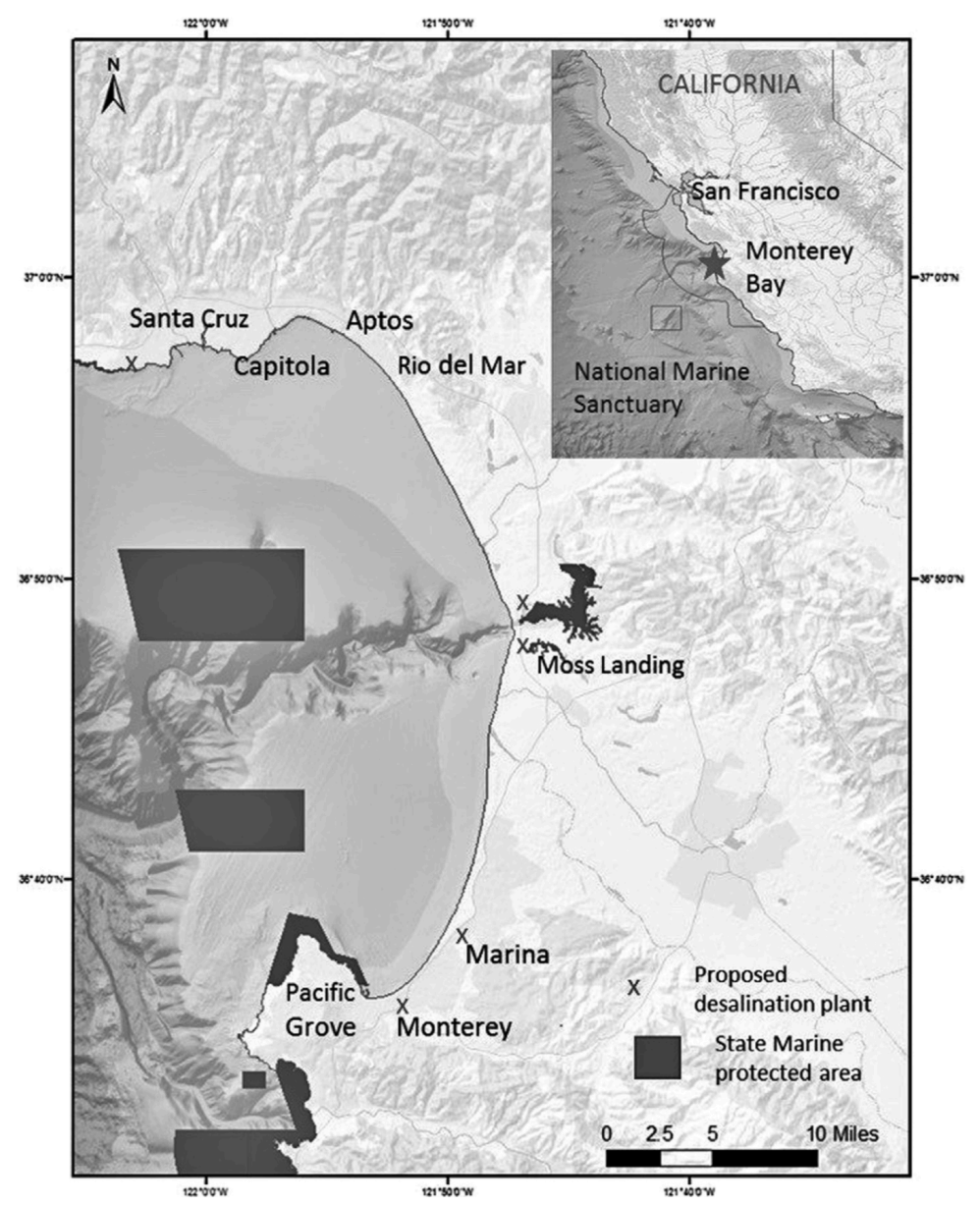

Fig. 1. Location of Monterey Bay and proposed desalination plants.

Drinking water supply in the area primarily relies on a number of groundwater basins and surface water systems, with groundwater accounting for roughly for $75 \%$ of the annual water supply in the region [14]. Saltwater intrusion into coastal aquifers and changes in precipitation patterns coupled with environmental regulations that protect aquatic ecosystems by restricting water taken from surface sources have reduced the reliability and availability of drinking water [14]. Three small desalination plants are already operating in the Sanctuary: Moss Landing $<<$ 0.5 million gallons per day (MGD), Marina (0.45 MGD), Monterey Bay Aquarium (0.040 MGD)). Five additional seawater desalination plants with capacities of 2.5-22 MGD have been proposed in recent years to diversify water supply sources (Fig. 1). 


\subsection{The Analytical Hierarchy Process}

The Analytical Hierarchy Process (AHP) is based on converting subjective assessments of relative importance to a set of overall scores or weights [18]. The method is based on structuring a problem in a hierarchical form, and then eliciting judgments for individual criteria based on pair-wise comparisons on a nine-point scale. This approach simplifies multidimensional scaling problems into one-dimensional by reducing decision-making to pair-wise comparisons [59]. As all objectives sum up to 1 (or 100\%), the AHP reveals preferences of individuals for one objective relative to another, making the nature of the trade-off between the different objectives transparent [71]. The AHP requires multiple steps including (1) the development of an objective hierarchy, (2) a pairwise comparison survey to elicit preferences towards objectives, and (3) the analysis of the results $[36,69]$.

\subsubsection{Development of a hierarchy}

Management objectives for desalination plants were developed based on information in the literature and environmental impact assessment reports for the proposed desalination facilities in the study area. Management objectives were grouped into environmental, socioeconomic, and water supply objectives (Fig. 2). Pairwise comparisons were made between the three main management objectives categories and between criteria under each 'parental' criterion (Fig. 3).

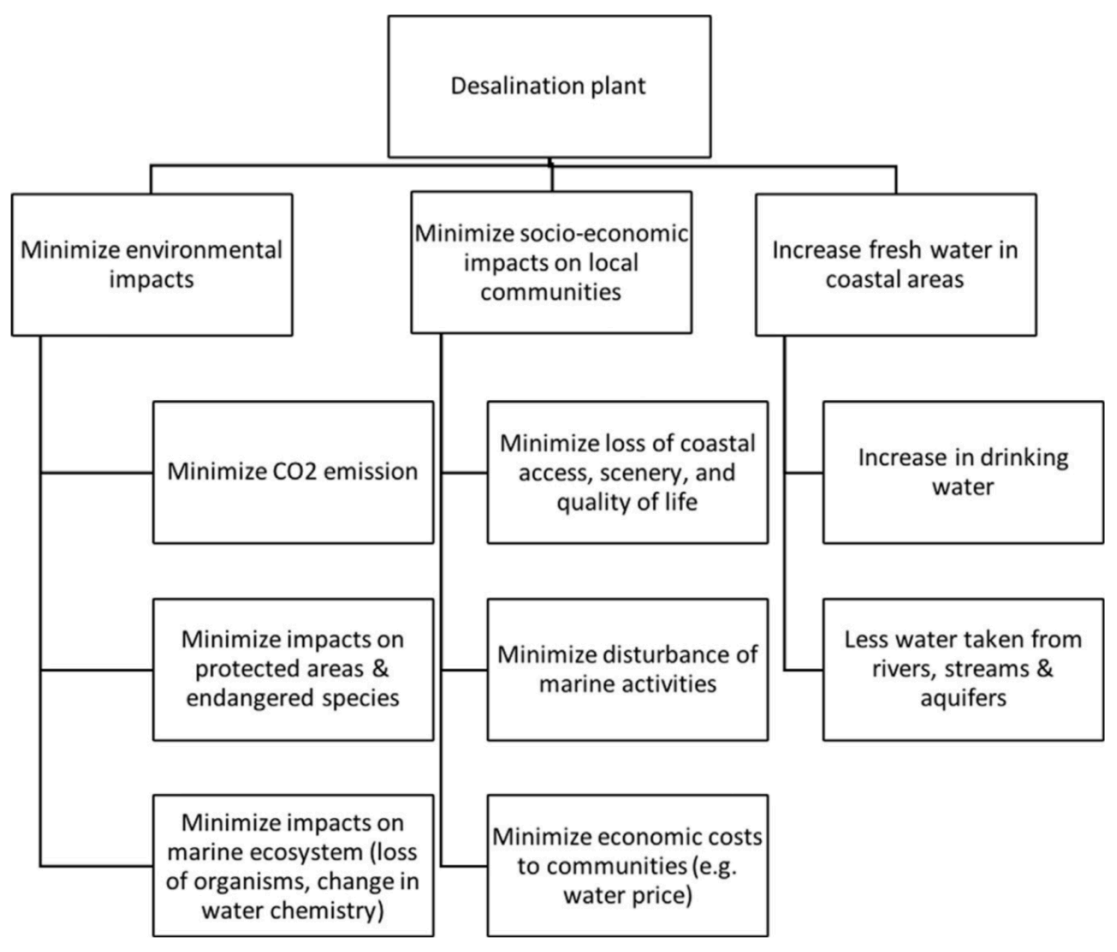

Fig. 2. Management objectives hierarchy.

\subsubsection{Data collection}

Data were collected via a questionnaire-based survey between June and July 2016. Households were randomly selected based on postal records across seven communities bordering 
Monterey Bay including Santa Cruz, Capitola, Aptos, Rio del Mar, Moss Landing, Marina, Monterey, and Pacific Grove. In addition, a census sampling approach was applied to survey commercial marine stakeholders operating in the Sanctuary including whale watching operators, sea kayaking operators, and scuba diving operators. In total, 1150 surveys were distributed. Questionnaires for households $(\mathrm{N}=1116)$ were administered in person and left at the door with a cover letter and a notice that the questionnaire would be picked up two days later. Stakeholders $(\mathrm{N}=34)$ were surveyed at their place of work. The overall response rate was $34 \%(N=391)$ with a response rate of $32.5 \%$ for local residents $(N=363), 81.8 \%$ for scuba diving operators $(N=9), 90 \%$ for whale watching operators $(N=8)$, and $100 \%$ response rate for sea kayaking operators $(\mathrm{N}=11)$.

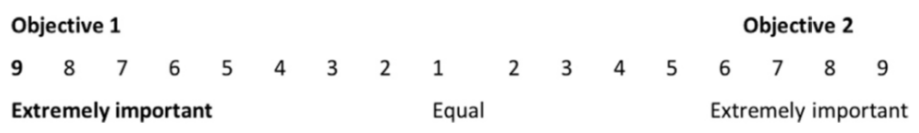

Fig. 3. AHP Pair-wise comparison scale.

The self-administered questionnaire contained a closed question asking about the most important management objectives that should be considered in the planning of proposed desalination plants. A total of 12 pairwise comparisons were included using a nine-point scale of importance: (1) indifferent, (3) weak preference or moderately important, (5) preference or more important, (7) strong preferences or strongly important, (9) very strong preferences or extremely more important [44]. The survey instrument also covered information on sociodemographics, livelihood dependency on the marine ecosystem in Monterey Bay on a scale from no dependency (0) to main source of income (2), stakeholder group affiliation, and frequency of participation in eight marine activities including commercial fishing, recreational fishing, surfing, scuba diving, wildlife watching, swimming, sea kayaking, and boating on a 5point scale from never (0) to almost every day (5).

\subsubsection{Data analysis}

Data analysis of weights was conducted in Excel. The relative weights were calculated based on a pairwise comparison reciprocal matrix $(A)$ of judgments with the following equation $\sum_{j-1}^{n} a i j w j=\lambda_{\max } w i, \forall i\left(a j i=\frac{1}{a i j}\right.$ and $\left.a i j>0\right)$ where indices $i$ and $j$ represent a pair of criteria; $\lambda_{\max }$ is the principal eigenvalue and the weights $w_{j}$ are normalized. Weights were then imported to SPSS 24 and combined with the survey data for further analysis.

A consistency check was conducted to determine the level of inconsistency in participants' responses, which is a critical step in the AHP approach. Responses may not always follow the axiom of transitivity in social choice theory that assumes that if objective $A$ is preferred to objective $B$ and objective $B$ is preferred to objective $C$, then objective $A$ should be preferred to objective $C$ [2]. For complex decisions, this logic may be broken by respondents and the consistency check allows to detect and account for potential inconsistencies in human behavior [58]. First, the consistency index $(\mathrm{Cl})$ was calculated with $\mathrm{Cl}=\left(\lambda_{\max }-n\right) /(n-1)$ where $n$ is the number of indicators and $\lambda_{\max }$ is the maximum eigenvalue. The consistency ratio (CR) was calculated as $\mathrm{CR}=\mathrm{Cl} / \mathrm{RI}$ where $\mathrm{RI}$ is a random index developed by Saaty based on the average $\mathrm{Cl}$ 
of 500 randomly filled matrices using a 9-point scale $[58,60]$. The CR has a value between 1 and 0 with a CR of 0 meaning perfect consistency [11]. For the purpose of this study, responses with a CR of equal to or less than 0.15 were included, which conforms with consistency ratio acceptance rates in previous studies of 0.1-0.2 [32,44,45]. Subsequently, 194 out of 341 completed questionnaires (56.9\%) were included in the analysis.

Statistical analysis was conducted in SPSS 24. The weights for management objectives were computed and aggregated using the arithmetic mean, a common standard for AHP analysis (e.g., $[61,45,52,51])$. Statistically significant differences among stakeholder groups were assessed using one-way ANOVA. Local residents were clustered into fishing and marine recreation groups based on their engagement in marine activities in the Sanctuary. Spearman rank correlations were calculated for management objectives, livelihood dependency, and frequency of ocean use in the sanctuary.

\section{Results}

\subsection{Importance of management objectives}

Coastal stakeholders placed the highest importance on minimizing environmental impacts, which was about twice as important as minimizing socio-economic impacts (Table 1). Weights of sub-criteria revealed that minimizing impacts on protected areas and endangered species in the Monterey Bay were the most important environmental objectives, followed by minimizing impacts on the marine ecosystem including both loss of small marine organisms due to water intake and changes in water chemistry due to brine discharge (Fig. 4). Minimizing $\mathrm{CO}_{2}$ emission was less important than environmental objectives that have direct impacts on the local marine ecosystem.

Table 1. Importance weights of main management objectives (mean).

\begin{tabular}{|c|c|}
\hline Management objectives & Mean \\
\hline Environmental impacts & 0.482 \\
\hline Socio-economic impacts & 0.206 \\
\hline Increase fresh water & 0.311 \\
\hline
\end{tabular}

Among socio-economic objectives, minimizing loss of coastal access, scenery, and value of residential areas were slightly more important than minimizing impacts on marine activities and minimizing economic impacts on local communities. Minimizing economic impacts was the least important objective. In terms of benefits of desalination, reducing pressure on surface and groundwater sources was given more weight than increasing drinking water for domestic use. Environmental benefits for aquatic ecosystems thus were rated as more important than benefits to local communities. Standard deviations were higher for the most important management objectives and lower for less important ones (Figs. 5 and 6).

\subsection{Importance of management objectives based on stakeholder group affiliation}

While commercial marine stakeholder groups and residents who engaged in fishing and marine recreation in the Sanctuary placed the highest importance on minimizing environmental 
impacts and the lowest importance on minimizing socio-economic impacts, their importance weights were different (Fig. 7). Priorities were more distinct for objectives in the subcategories (Fig. 8). The most important objective for scuba diving operators was minimizing impacts on protected marine ecosystems and endangered species. Wildlife watching and scuba diving operators also placed significantly more weight on minimizing impacts on marine activities in the Sanctuary than residents engaged in marine recreation and fishing $(p=0.042)$ indicating that commercial stakeholders were concerned about potential impacts on their use of the Sanctuary (Table 2). Commercial users, including wildlife watching operators and kayaking operators, and coastal residents weighted minimizing economic impacts as significantly more important than scuba diving operators, who placed the least importance on economic impact minimization $(p=0.050)$. Differences in weights were therefore not only obvious between commercial marine stakeholders and coastal residents, but also among commercial stakeholder groups. Overall, these findings demonstrate that stakeholder groups had distinct preferences for management objectives.

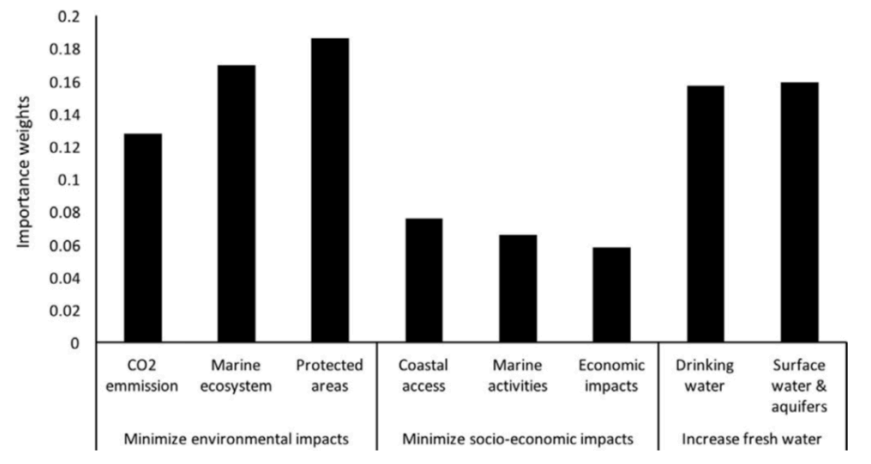

Fig. 4. Importance weights of management objectives in sub-categories (mean value).

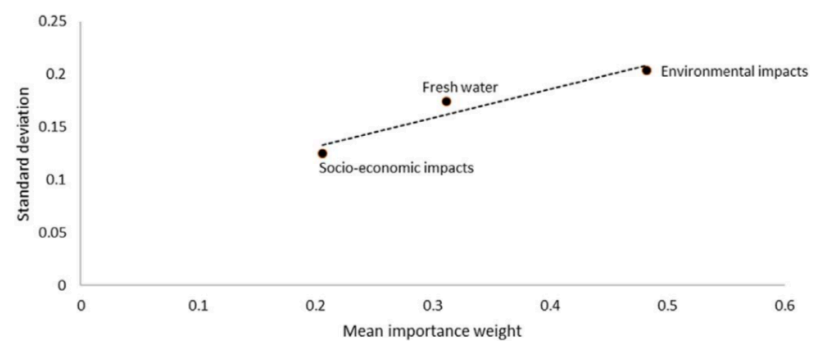

Fig. 5. Standard deviation of mean importance weights for aggregated management objectives relative to the means with trend line. 


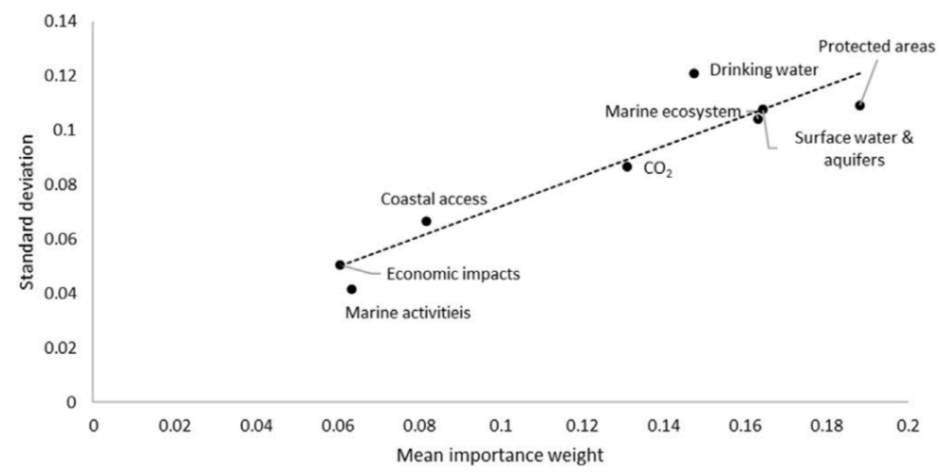

Fig. 6. Standard deviation of mean importance weights for management objectives relative to the means with trend line.



Fig. 7. Importance weights of main objectives among stakeholder groups (mean value).

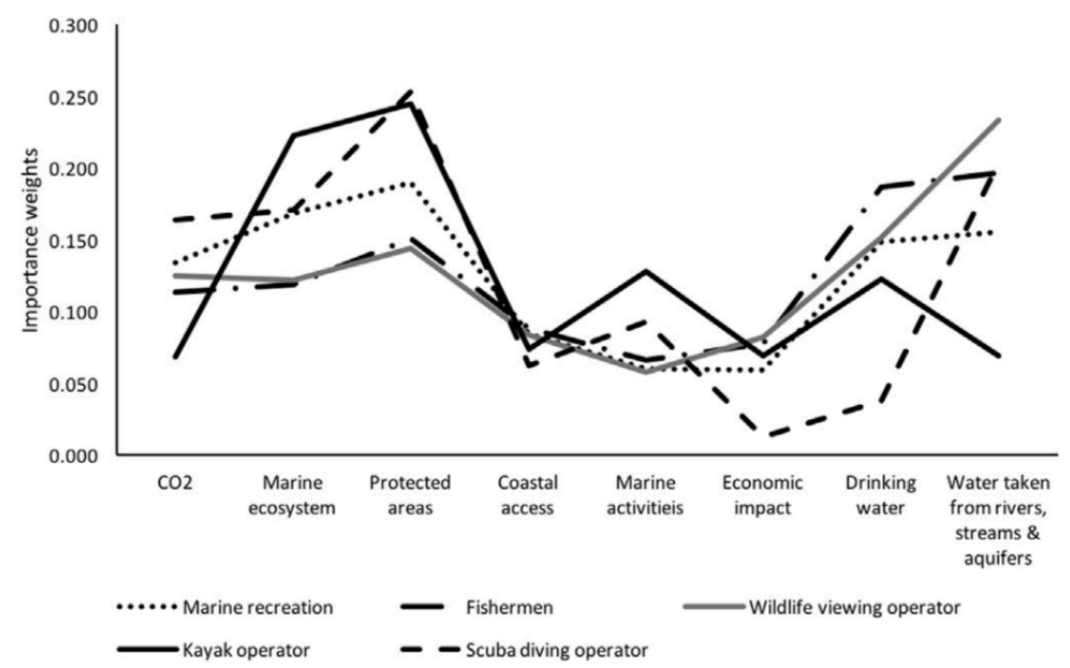

Fig. 8. Importance weights for management objectives in subcategories among stakeholder groups (mean value). 
Table 2. Importance of management objectives among stakeholder groups (mean importance weights)

\begin{tabular}{|c|l|l|l|l|l|l|l|}
\hline & $\begin{array}{l}\text { Marine } \\
\text { recreation }\end{array}$ & Fishermen & $\begin{array}{l}\text { Wildlife } \\
\text { viewing } \\
\text { operator }\end{array}$ & $\begin{array}{l}\text { Kayak } \\
\text { operator }\end{array}$ & $\begin{array}{l}\text { Scuba } \\
\text { diving } \\
\text { operator }\end{array}$ & $\mathbf{F}$ & $\mathbf{p}$ \\
\hline Environmental Impacts & 0.492 & 0.384 & 0.391 & 0.537 & 0.589 & 2.378 & 0.054 \\
\hline$-\quad \mathrm{CO}_{2}$ & 0.134 & 0.114 & 0.125 & 0.069 & 0.164 & 1.040 & 0.388 \\
\hline$-\quad$ Marine ecosystem & 0.168 & 0.119 & 0.122 & 0.223 & 0.171 & 1.743 & 0.143 \\
\hline$-\quad$ Protected areas & 0.190 & 0.151 & 0.144 & 0.245 & 0.253 & 1.887 & 0.115 \\
\hline Socio-economic impacts & 0.204 & 0.232 & 0.223 & 0.272 & 0.169 & 0.707 & 0.588 \\
\hline$-\quad$ Coastal access & 0.084 & 0.089 & 0.084 & 0.074 & 0.063 & 0.223 & 0.926 \\
\hline$-\quad$ Marine activities & 0.060 & 0.066 & 0.058 & 0.128 & 0.093 & 3.709 & 0.006 \\
\hline$-\quad$ Economic impact & 0.060 & 0.078 & 0.082 & 0.069 & 0.013 & 2.582 & 0.039 \\
\hline Increase fresh water & 0.304 & 0.383 & 0.385 & 0.192 & 0.242 & 2.098 & 0.083 \\
\hline$-\quad$ Drinking water & 0.148 & 0.187 & 0.152 & 0.123 & 0.038 & 2.074 & 0.086 \\
\hline$-\quad$ Surface water \& & 0.156 & 0.197 & 0.233 & 0.069 & 0.204 & 2.274 & 0.063 \\
\hline aquifers & & & & & & & \\
\hline
\end{tabular}

Table 3. Correlation coefficients livelihood dependency and ocean use with performance indicators (Spearman rank non-parametric correlation).

\begin{tabular}{|c|l|l|l|}
\hline & Fishing & $\begin{array}{l}\text { Livelihood dependency } \\
\text { on Sanctuary }\end{array}$ & Time spent in Sanctuary \\
\hline Environmental Impacts & 0.022 & 0.069 & $0.246^{* *}$ \\
\hline$-\quad \mathrm{CO}_{2}$ & 0.005 & 0.055 & 0.075 \\
\hline$-\quad$ Marine ecosystem & -0.043 & -0.017 & $0.157^{*}$ \\
\hline$-\quad$ Protected areas & 0.037 & 0.096 & $0.245^{* *}$ \\
\hline Socio-economic impacts & -0.076 & -0.043 & $-0.228^{* *}$ \\
\hline$-\quad$ Coastal access & -0.115 & -0.123 & $-0.167^{*}$ \\
\hline$-\quad$ Marine activities & -0.017 & 0.048 & -0.109 \\
\hline$-\quad$ Economic impact & -0.067 & -0.044 & $-0.268^{* *}$ \\
\hline Increase fresh water & 0.010 & -0.050 & $-0.159^{*}$ \\
\hline$-\quad$ Drinking water & -0.042 & -0.130 & $-0.235^{* *}$ \\
\hline$-\quad$ Surface water \& aquifers & 0.055 & 0.032 & -0.081 \\
\hline
\end{tabular}

Table 4. Consistency of responses (Consistency ratio < 15\%).

\begin{tabular}{|l|l|}
\hline Stakeholder group & \% within group \\
\hline Marine recreational users & 51.5 \\
\hline Fishermen & 45.5 \\
\hline Wildlife viewing operator & 62.5 \\
\hline Kayak operator & 36.4 \\
\hline Scuba diving operator & 77.8 \\
\hline
\end{tabular}




\subsection{Influence of ocean use and livelihood dependency on importance of management objectives}

Non-parametric correlation analysis revealed no significant correlation between livelihood dependency and fishing with the importance of any management objectives (Table 3).

In contrast, the amount of time spent in the Sanctuary was positively correlated with the importance of minimizing environmental impacts, in particular on the marine ecosystem and protected areas, at the expense of the importance given to socio-economic and water management objectives. Coastal stakeholders who frequently use marine areas in the Sanctuary thus weighted minimizing environmental impacts as very important.

\subsection{Consistency of responses}

The consistency of responses within each of the stakeholder groups was also analyzed (Table 4). Overall, $51.0 \%$ of respondents had inconsistencies equal or less than $15 \%$ in their responses. Public stakeholder groups had similar inconsistencies with $45.4 \%$ of residents engaged in fishing and $51.5 \%$ of residents engaged in marine recreational activities in the Sanctuary having a consistency ratios of $15 \%$ or less. Scuba diving $(77.8 \%)$ and wildlife viewing operators $(62.5 \%)$ were most consistent in their responses. Sea kayaking operators had the lowest consistency in their responses with only $36.4 \%$ of operators having a consistency ratio of equal or less than $15 \%$. Differences in consistency ratios were thus not only obvious between residents and commercial stakeholders but also among stakeholder groups suggesting differences in their understanding of desalination issues in the Sanctuary.

\section{Discussion}

Management objectives for coastal developments need to be identified in the early stages of the planning process. As stakeholder engagement has become integral to coastal zone management in many regions, eliciting views of local communities is critical for the management of coastal resources. Public consultation, for example, is central to the development of new desalination plants [5] and to MPA management in California [62]. Since desalination plants may adversely affect MPAs in near-shore areas, public opinions on desalination factor into both the development of desalination plants and the management of MPAs in areas where plants have been proposed close to MPAs. This study addresses the current lack of understanding of coastal stakeholders' opinions on desalination plants by quantifying coastal stakeholders' priorities for management objectives that should be considered in the planning of new desalination facilities in communities adjacent to a National Marine Sanctuary.

The findings reveal that minimizing environmental impacts was the most important management objective for coastal stakeholders. Even though costs are a common criticism of desalination technology [9], minimizing socio-economic impacts were only half as important as environmental impacts. These results suggest that the planning process for desalination plants in the Sanctuary should be guided primarily by environmental objectives. 
The highest importance was given to minimizing direct impacts on the local marine ecosystem including protected areas and endangered species in the Sanctuary. This finding emphasizes the importance of the local context in which proposed facilities are embedded. Monterey Bay is an important area for migrating and resident marine mammals and seabirds, and is an area of very high primary productivity. Minimizing impacts on this dynamic and productive ecosystem seems paramount to coastal residents. This result is similar to previous studies on stakeholders' opinions on MPA management that reported high importance of environmental MPA objectives $[28,52]$. In the case of desalination, these objectives could be compromised by water intake and brine discharge of proposed desalination plants.

The importance given to minimizing environmental impacts also indicated the need to integrate desalination plants into wider coastal zone management. At the moment, desalination plants in Monterey Bay are proposed on an ad hoc, project by project basis, and by different water management agencies. Given the increasing evidence that sectoral approaches to marine resource management often fail $[12,13]$, a more systematic planning effort seems critical to place proposed plants into local contexts and to integrate desalination plants into MPA and coastal zone management efforts. Potential impacts due to water intake and brine discharge, including cumulative impacts if multiple plants are constructed around the Sanctuary, are not well understood and could interfere with conservation goals of the National Marine Sanctuary. Assessing potential impacts on marine ecosystems will be critical for informing systematic planning on a regional scale, and for understanding and addressing potential conflicts with existing marine conservation efforts. The potential conflict between seawater desalination and MPAs also emphasizes the need for more integrated land and sea conservation efforts that account for terrestrial activities adjacent to MPAs [1,27].

Coastal stakeholders also weighted reducing pressure on surface water sources and aquifers as more important than purely increasing water for residential consumption that may foster coastal growth rather than replace water taken from other sources. Assessing in how far proposed desalination plants can help to reduce pressure on surface and groundwater sources thus emerged as an important planning consideration. Replacing water taken from surface and groundwater resources with desalinated water, for example, can help reduce saltwater intrusion and maintain water levels in rivers and streams needed to sustain aquatic ecosystems and fish species, especially during droughts. These objectives are usually not central arguments for building seawater desalination plants that typically focus on increasing domestic water supply. The findings suggest that these objectives may play a prominent role in areas where saltwater intrusion and impacts on aquatic ecosystems, driven by water overdrafts, are critical issues, as is the case in the Monterey Bay area. These findings emphasize the need to adapt goals and objectives for desalination plants to the local context.

The emphasis on minimizing environmental impacts and on reducing pressure on aquatic ecosystems also indicates that the inclusion of local stakeholders may lead to more sustainable outcomes and management of marine ecosystems [55]. Water management agencies, for example, may be primarily interested in increasing drinking water supply, while a desalination operator may focus on economic profits from a plant. A participatory approach may thus not 
only foster a more democratic process but also lead to outcomes that benefit not only local communities but also coastal ecosystems.

Analyzing differences among stakeholder groups revealed that coastal residents and commercial marine stakeholders had distinct priorities for management objectives. These differences highlight the need to elicit different groups' priorities. Information collected in public hearings and comments may fail to detect priorities of individual user groups and may lead to conflicts of desalination with existing marine uses. In addition, neither livelihood dependency on marine areas in the Sanctuary nor engagement in fishing had an effect on the importance of management objectives, even though desalination may lead to mortality of small marine organisms and fish larvae $[3,47]$. The amount of time spent in the Sanctuary increased the importance of environmental objectives at the expense of socio-economic objectives. Marine user patterns thus seem to shape the importance of desalination management objectives. The absence of an effect of livelihood dependency on the importance of management objectives may explain why the main differences for importance weights did not consistently occur between commercial and marine user groups.

The analysis of consistency ratios further revealed that around half of all surveyed stakeholders had high inconsistencies in their responses $(C R>0.15)$. Scuba diving operators and whale watching operators were most consistent in their answers. High proportions of inconsistent responses are common in AHP studies [51,71], particularly when eliciting public preferences $[45,54,68]$. Inconsistent responses can stem from multiple factors, including a lack of understanding of the management issue under consideration [44,52]. As desalination is a fairly new technology in California, coastal stakeholders may require more information on the technology and its impacts to make more informed decisions [29]. However, as high inconsistency levels have also been detected in studies on management preferences in other marine sectors, such as fisheries [51,71], inconsistencies in this study might not necessarily stem from a lack of understanding of this new technology. Human preferences are typically not inherently transitive and the higher the number of objectives, the more likely is a high inconsistency in responses [11]. Since desalination is a highly complex issue, another explanation could be the high complexity of the underlying management problem [52]. Making trade-offs between potential impacts and benefits may not be an easy task, given that a reliable water supply is critical, but so is a healthy marine environment and the effectiveness of established MPAs.

\section{Conclusions}

The study demonstrates the applicability of the Analytical Hierarchy Process as a collaborative decision-making tool in the context of seawater desalination. Eliciting coastal stakeholders' priorities for management objectives of seawater desalination plants prior to their establishment provided multiple insights that could be used to guide the development of desalination plants on regional and local scales. The importance of management objectives may be different in other locations since the local context, including the presence of a National Marine Sanctuary, seemed to play an important role for the development of seawater desalination plants. Differences in stakeholders' opinions further suggest the need for a more 
systematic assessments of stakeholder groups' opinions on seawater desalination, since public hearings and comments on environmental impact reports may fail to detect divergent opinions. Water resource managers elsewhere could adopt similar approaches to elicit stakeholders' preferences, and to increase transparency and accountability of decision-making processes. The AHP approach could also be used to elicit opinions of other stakeholder groups such as the agricultural community in coastal areas, to expand the understanding of desalination preferences beyond coastal residents and marine users.

\section{Acknowledgements}

The study was funded by the National Science Foundation Coastal SEES Program, award 1325649 to A.P., D.P., and B.H. We thank Brolin Mirza and Sarah Faraola for their help in the field.

\section{References}

[1] J.G. Alvarez-Romero, R.L. Pressey, N.C. Ban, K. Vance-Borland, C. Willer, C.J. Klein, S.D. Gaines, Integrated land-sea conservation planning: the missing links, Annu. Rev. Ecol. Evol. Syst. 42 (2011) 381-409.

[2] K. Arrow, Social Choice and Individual Values, John Wiley and Sons, New York, 1951.

[3] P.A. Azis, I. Al-Tisan, M. Daili, T. Green, A. Dalvi, M. Javeed, Chlorophyll and plankton of the Gulf coastal waters of Saudi Arabia bordering a desalination plant, Desalination 154 (3) (2003) 291-302.

[4] N. Belkin, E. Rahav, H. Elifantz, N. Kress, I. Berman-Frank, Enhanced salinities, as a proxy of seawater desalination discharges, impact coastal microbial communities of the eastern Mediterranean Sea, Environ. Microbiol. 17 (10) (2015) 4105-4120.

[5] California Coastal Commission, Seawater Desalination and the California Coastal Act, California Coastal Commission, San Francisco, CA, 2004.

[6] California Department of Water Resources, Desalination, California Department of Water Resources, Sacramento, 2003.

[7] J. Clímaco, J. Craveirinha, Multiple Criteria Decision Analysis-State of the Art Surveys, Springer, New York, 2005.

[8] H. Cooley, N. Ajam, M. Heberger, Key Issues in Seawater Desalination in California: Marine Impacts, Pacific Institute, Oakland, CA, 2013.

[9] H. Cooley, M. Heberger, Key Issues in Seawater Desalination in California: Energy and Greenhouse Gas Emission, Pacific Institute, Oakland, CA, 2013. 
[10] P. Côté, S. Siverns, S. Monti, Comparison of Membrane-based solutions for water reclamation and desalination, Desalination 182 (1-3) (2005) 251-257, http://dx.doi.org/10.1016/j.desal.2005.04.015.

[11] G. Coyle, The analytic hierarchy process (AHP), Pract. Strategy.: Struct. Tools Tech. (2004) 1-11.

[12] L. Crowder, E. Norse, Essential ecological insights for marine ecosystem-based management and marine spatial planning, Mar. Policy 32 (5) (2008) 772-778, http://dx.doi.org/10.1016/j.marpol.2008.03.012.

[13] L.B. Crowder, G. Osherenko, O.R. Young, S. Airamé, E.A. Norse, N. Baron, J.C. Day, F. Douvere, C.N. Ehler, B.S. Halpern, S.J. Langdon, K.L. McLeod, J.C. Ogden, R.E. Peach, A.A. Rosenberg, J.A. Wilson, Resolving mismatches in U.S. ocean governance, Science 313 (5787) (2006) 617-618, http://dx.doi.org/10.1126/science.1129706.

[14] B. Damitz, D. Furukawa, J. Toal, Desalination Feasibility Study for the Monterey Bay Region. Final Report Prepared for the Association of Monterey Bay Area Governments (AMBAG), (2006).

[15] M.A. Dawoud, The role of desalination in augmentation of water supply in GCC countries, Desalination 186 (1-3) (2005) 187-198, http://dx.doi.org/10.1016/i.desal.2005.03.094.

[16] J.A. de-la-Ossa-Carretero, Y. Del-Pilar-Ruso, A. Loya-Fernández, L.M. FerreroVicente, C. Marco-Méndez, E. Martinez-Garcia, J.L. Sánchez-Lizaso, Response of amphipod assemblages to desalination brine discharge: impact and recovery, Estuar. Coast. Shelf Sci. 172 (2016) 13-23.

[17] Y. Del-Pilar-Ruso, J.A. De-la-Ossa-Carretero, F. Giménez-Casalduero, J.L. SánchezLizaso, Effects of a brine discharge over soft bottom Polychaeta assemblage, Environ. Pollut. 156 (2) (2008) 240-250.

[18] J. Dodgson, M. Spackman, A.D. Pearman, L.D. Phillips, Multi-criteria Analysis: A Manual, Department of the Environment, Transport and Regions, Department for Communities and Local Government, London, 2009.

[19] S. Dolnicar, A. Hurlimann, B. Grün, What affects public acceptance of recycled and desalinated water? Water Res. 45 (2) (2011) 933-943, http://dx.doi.org/10.1016/j.watres.2010.09.030.

[20] S. Dolnicar, A. Hurlimann, L.D. Nghiem, The effect of information on public acceptance the case of water from alternative sources, J. Environ. Manag. 91 (6) (2010) 1288-1293, http://dx.doi.org/10.1016/j.jenvman.2010.02.003. 
[21] S. Dolnicar, A.I. Schäfer, Desalinated versus recycled water: public perceptions and profiles of the accepters, J. Environ. Manag. 90 (2) (2009) 888-900, http://dx.doi.org/10.1016/j.jenvman.2008.02.003.

[22] J.L. Fuentes-Bargues, Analysis of the process of environmental impact assessment for seawater desalination plants in Spain, Desalination 347 (2014) 166-174, http://dx.doi.org/10.1016/j.desal.2014.05.032.

[23] F.R. Gell, C.M. Roberts, Benefits beyond boundaries: the fishery effects of marine reserves and fishery closures, Trends Ecol. Evol. 18 (2003) 448-455.

[24] F.L. Gibson, S. Tapsuwan, I. Walker, E. Randrema, Drivers of an urban community's acceptance of a large desalination scheme for drinking water, J. Hydrol. 528 (2015) 38-44, http://dx.doi.org/10.1016/j.jhydrol.2015.06.012.

[25] M. Gopnik, C. Fieseler, L. Cantral, K. McClellan, L. Pendleton, L. Crowder, Coming to the table: early stakeholder engagement in marine spatial planning, Mar. Policy 36 (5) (2012) 1139-1149, http://dx.doi.org/10.1016/j.marpol.2012.02.012.

[26] B.S. Halpern, The impact of marine reserves: do reserves work and does reserve size matter? Ecol. Appl. 13 (1) (2003).

[27] B.S. Halpern, S. Walbridge, K.A. Selkoe, C.V. Kappel, F. Micheli, C. D'Agrosa, J.F. Bruno, K.S. Casey, C. Ebert, H.E. Fox, A global map of human impact on marine ecosystems, Science 319 (5865) (2008) 948-952.

[28] N. Heck, P. Dearden, A. McDonald, Stakeholders' expectations towards a proposed marine protected area: a multi-criteria analysis of MPA performance criteria, Ocean Coast. Manag. 54 (9) (2011) 687-695, http://dx.doi.org/10.1016/j.ocecoaman.2011.07.003.

[29] N. Heck, A. Paytan, D.C. Potts, B. Haddad, Coastal residents' literacy about seawater desalination and its impacts on marine ecosystems in California, Mar. Policy 68.

[30] N. Heck, A. Paytan, D.C. Potts, B. Haddad, Predictors of local support for a seawater desalination plant in a small coastal community, Environ. Sci. Policy 66 (2016) 101-111.

[31] G. Herath, T. Prato, Using Multi-criteria Decision Analysis in Natural Resource Management, Ashgate Publishing, Ltd., Aldershot, 2006.

[32] A.H. Himes, Performance indicator importance in MPA management using multicriteria approach, Coast. Manag. 43 (5) (2007) 601-618.

[33] T.E. Hinkebein, M.K. Price, Progress with the desalination and water purification 
technologies US roadmap, Desalination 182 (1-3) (2005) 19-28, http://dx.doi.org/10.1016/j.desal.2005.03.006.

[34] T. Hoepner, S. Latteman, Environmental impact and impact assessment of seawater desalination, Desalination 22 (2008) 1-15.

[35] J.E. Innes, D.E. Booher, Reframing public participation: strategies for the 21st century, Plan. Theory Pract. 5 (4) (2004) 419-436, http://dx.doi.org/10.1080/1464935042000293170.

[36] P.J. Innes, S. Pascoe, A multi-criteria assessment of fishing gear impacts in demersal fisheries, J. Environ. Manag. 91 (2010) 9932-9939.

[37] Intergovernmental Panel on Climate Change, IPCC, 2000-Impacts, Adaptation, and Vulnerability-The Contribution of Working Group II to the Third Scientific Assessment of the Intergovernmental Panel on Climate Change, Cambridge University Press, Cambridge, 2001.

[38] International Desalination Association, Desalination by Numbers, 2014.

[39] S. Jennings, S. Pascoe, S. Hall-Aspland, B. Le Bouhellec, A. Norman-Lopez, A. Sullivan, G. Pecl, Setting objectives for evaluating management adaptation actions to address climate change impacts in south-eastern Australian fisheries, Fish. Oceanogr. 25 (S1) (2016) 29-44.

[40] G.P. Jones, M. Srinivasa, G.R. Almany, Population connectivity and conservation of marine biodiversity, Oceanography 20 (3) (2007) 42-53.

[41] T.J. King, D. Ooi, J. Cary, A. Fisher, R. Schibeci, K. Murphy, K. O’Toole, M. Mearns, J.A. Donaldson, Public perceptions of, and responses to, desalination in Australia, in: Alfred Deakin Research Institute Working Paper Series, Deakin University, 2012.

[42] P. Leung, Multiple-criteria decision-making (MCDM) applications in fishery management, Int. J. Environ. Technol. Manag. 6 (1/2) (2006) 96-110.

[43] T.-K. Liu, H.-Y. Sheu, C.-N. Tseng, Environmental impact assessment of seawater desalination plant under the framework of integrated coastal management, Desalination 326 (0) (2013) 10-18, http://dx.doi.org/10.1016/j.desal.2013.07.003.

[44] S. Mardle, S. Pascoe, I. Herrero, Management objective importance in fisheries: an evaluation using the analytic hierarchy process (AHP), Environ. Manag. 33 (1) (2004) 1-11.

[45] J.-B. Marre, S. Pascoe, O. Thébaud, S. Jennings, J. Boncoeur, L. Coglan, Information preferences for the evaluation of coastal development impacts on ecosystem services: a multicriteria assessment in the Australian context, J. Environ. Manag. 173 (2016) 141-150, http://dx.doi.org/10.1016/j.jenvman.2016.01.025. 
[46] S. Miller, H. Shemer, R. Semiat, Energy and environmental issues in desalination, Desalination 366 (2015) 2-8.

[47] R. Miri, A. Chouikhi, Ecotoxicological marine impacts from seawater desalination plants, Desalination 182 (1-3) (2005) 403-410, http://dx.doi.org/10.1016/i.desal.2005.02.034.

[48] N. Natural Resources Defense Council. Proceed with caution: California's drought and seawater desalination, in: NRDC Issue Brief May 2014, Natural Resources Defense Council, New York, 2014.

[49] NOAA, Monterey Bay National Marine Sanctuary Overview, 2017.

[50] NOAA Monterey Bay National Marine Sanctuary, National Marine Fisheries Service, Guidelines for desalination plants in the Monterey Bay National Marine Sanctuary, 2010.

[51] S. Pascoe, W. Proctor, C. Wilcox, J. Innes, W. Rochester, N. Dowling, Stakeholder objective preferences in Australian Commonwealth managed fisheries, Mar. Policy 33 (5) (2009) 750758.

[52] S. Pendred, A. Fischer, S. Fischer, Improved management effectiveness of a marine protected area through prioritizing performance indicators, Coast. Manag. 44 (2) (2016) 93-115.

[53] T. Potts, C. Pita, T. O'Higgins, L. Mee, Who cares? European attitudes towards marine and coastal environments, Mar. Policy 72 (2016) 59-66.

[54] M.E. Qureshi, S.R. Harrison, Application of the analytic hierarchy process to riparian revegetation policy options, Small-Scale For. Econ. Manag. Policy 2 (3) (2003) 441, http://dx.doi.org/10.1007/s11842-003-0030-6.

[55] M.S. Reed, Stakeholder participation for environmental management: a literature review, Biol. Conserv. 141 (10) (2008) 2417-2431.

[56] A.A. Rogers, Public and expert preference divergence: evidence from a choice experiment of marine reserves in Australia, Land Econ. 89 (2) (2013) 346-370.

[57] G. Russ, A. Alcala, Marine reserves: rates and patterns of recovery and decline of large predatory fish, Ecol. Appl. 6 (3) (1996) 947-961.

[58] T.L. Saaty, A scaling method for priorities in hierarchical structures, J. Math. Psychol. 15 (3) (1977) 234-281.

[59] T.L. Saaty, L.G. Vargas, Models, Methods, Concepts and Applications of the Analytic 
Hierarchy Process, Kluwer, Boston, 2000.

[60] T.L. Saaty, L.G. Vargas, Models, Methods, Concepts \& Applications of the Analytic Hierarchy Process Vol. 175 Springer Science \& Business Media, 2012.

[61] M. Salazar-Ordóñez, M. Rodríguez-Entrena, S. Sayadi, Agricultural sustainability from a societal view: an analysis of Southern Spanish Citizens, J. Agric. Environ. Ethics 26 (2) (2013) 473-490, http://dx.doi.org/10.1007/s10806-011-9371-x.

[62] K. Sayce, C. Shuman, D. Connor, A. Reisewitz, E. Pope, M. Miller-Henson, E. Poncelet, D. Monié, B. Owens, Beyond traditional stakeholder engagement: public participation roles in California's statewide marine protected area planning process, Ocean Coast. Manag. 74 (2013) 57-66.

[63] M. Schiffler, Perspectives and challenges for desalination in the 21st century, Desalination 165 (2004) 1-9, http://dx.doi.org/10.1016/j.desal.2004.06.001.

[64] J. Sellers, Desalination policy in a multilevel regulatory state, in: Cesar Nava Escuder, Gerardo Hiriart Le Bert (Eds.), Desalaction de agua con energias renovables, National Autonomous University of Mexico Press, Mexico City, 2008, pp. 173-188.

[65] G.L. Theodori, B.J. Wynveen, W.E. Fox, D.B. Burnett, Public perception of desalinated water from oil and gas field operations: data from Texas, Soc. Nat. Resour. 22 (7) (2009) 674-685, http://dx.doi.org/10.1080/08941920802039804.

[66] A. Thomassin, C.S. White, S.S. Stead, G. David, Social acceptability of a marine protected area: the case of Reunion Island, Ocean Coast. Manag. 53 (4) (2010) 169-179.

[67] F. Vanclay, The potential application of social impact assessment in integrated coastal zone management, Ocean Coast. Manag. 68 (2012) 149-156, http://dx.doi.org/10.1016/j.ocecoaman.2012.05.016.

[68] P. Wattage, S. Mardle, Stakeholder preferences towards conservation versus development for a wetland in Sri Lanka, J. Environ. Manag. 77 (2) (2005) 122-132.

[69] P. Wattage, S. Mardle, Valuing wetland aquatic resources using the analytical hierarchy process, in: Gamini Herath, T. Prato (Eds.), Using Multi-Criteria Decision Analysis in Natural Resource Management, Ashgate, Aldershot, 2006, pp. 205-219.

[70] D. Whitmarsh, M.G. Palmieri, Social acceptability of marine aquaculture: the use of survey-based methods for eliciting public and stakeholder preferences, Mar. Policy (33) (2009) 452-457.

[71] D. Whitmarsh, P. Wattage, Public attitudes towards the environmental impact of 
salmon aquaculture in Scotland, Eur. Environ. 16 (2) (2006) 108-121. 